\title{
Introduction to the ECCA papers
}

\author{
Security Journal (2008) 21, 1-3. doi:10.1057/palgrave.sj.8350065
}

This special issue of the Security Journal carries six original papers first given at the 14th Annual Environmental Criminology and Crime Analysis Symposium in Vancouver, British Columbia, Canada during the summer of 2006. It represents a continued association between the Environmental Criminology and Crime Analysis (ECCA) group and the Security Journal that dates back more than a decade and bridges many different interests among crime science researchers, police, and security and loss prevention specialists.

ECCA is an international invitational conference which by tradition invites about 40 academic crime scientists and about 40 law enforcement and security professionals to a mid-summer retreat at which they can share ideas and research findings about crime patterns and crime prevention as well as compare the latest techniques for crime analysis and crime reduction. The focus at ECCA, from the outset, has been on development of a better understanding of criminal events so that better strategies of crime and loss prevention can be developed, implemented, evaluated and shared.

The emphasis that the ECCA symposia have placed on empirical understanding of criminal events makes them sharply different from traditional criminology and criminal justice conferences. Criminology traditionally focuses on understanding the origins of human criminality. Criminal Justice studies traditionally focus on the efficiency and effectiveness of criminal justice agency operations. The criminal event perspective taken at the ECCA symposia considers a much larger set of event elements. In addition to criminality and criminal justice system operations, this perspective also considers the time and place of the criminal event; the macro, meso and micro physical, social and legal contexts of criminal events; the characteristics and routine activities of targets and victims as well as offenders; and, the actual methods and mechanics of different types of crime. Focus is on developing sufficient understanding of the patterns in criminal events to enable researchers and practitioners to design situational interventions that reduce the future incidence of crime.

The ECCA symposia have played a major role in facilitating collaboration between academics and law enforcement and loss prevention specialists. In many ways, discussions begun at early ECCA meetings have contributed to the development of the International CPTED Association (many of its founding members attended the early ECCA symposia); have fostered the collaboration between Professor Herman Goldstein and Dean Ronald Clarke that have done so much to expand problem-oriented policing and create the Center for Problem-Oriented Policing and its spectacular online resources; and have provided the impetus for much of the criminal event focused research that underlies the successful evidence-based pursuit of crime reduction in Australia, Canada, Britain and New Zealand as well as in some American cities. 
As this issue also illustrates, the ECCA symposia have provided a forum for the introduction and testing of new ideas and new techniques for studying crime and developing international collaborative research relationships. Early ECCA symposia provided a forum for intensive study of the utility of crime mapping and the study of the journey to crime. The National Institute of Justice's active crime mapping program was developed by early ECCA participants, and ECCA continues to be a test bed for the development of new approaches to understanding the spatial dimensions of crime. The theory of situational crime prevention has been tested, challenged and improved through ECCA discussions. Crime pattern analysis has moved from simple mapping exercises to sophisticated simulation modeling aimed at both experimental testing of specific theory and practical analysis to aid investigations and crime prevention programs. Computational criminology has grown from discussions at ECCA.

The symposia originated at the École de Criminologie at the Université de Montréal in 1992 as the Invitational Seminar on Criminological Analysis. The meeting was seen as so productive by Paul Cromwell, the then director of the Criminology Program at the University of Miami, that he hosted an invitational Seminar on Crime Analysis and Environmental Criminology in Florida in 1993. ECCA took form under its continuing name for the first time in 1994, hosted by the School of Criminal Justice at Rutgers University, Newark at the invitation of Dean Ronald V. Clarke and Professor Marcus Felson. Subsequent meetings have been held in many parts of the world: Cambridge in 1995; Tokyo in 1996; Oslo in 1997; Barcelona in 1998; South Africa in 1999; Perth, Western Australia in 2000; Liverpool in 2001; Cincinnati in 2003; Wellington, New Zealand in 2004 and Santiago, Chile in 2005. The 2002 symposium, scheduled to meet in India, had to be cancelled when international tensions caused various countries' foreign ministries to discourage travel to the subcontinent.

The 2006 ECCA symposium, from which the articles in this special issue were selected, was held in Vancouver, British Columbia, in Canada, hosted by the Royal Canadian Mounted Police, Simon Fraser University and the University College of the Fraser Valley.

Over the years of the ECCA symposia, the range of studies has expanded. In the past two or three symposia, researchers have begun to test criminal event models grounded in routine activities theory, rational choice theory and crime pattern theory by building and using new tools and by synthesizing multiple elements of the criminal event.

Three papers in the current issue focus on the complexity and crime reduction potential of space-time analysis. Spencer Chainey probes the ability of hot spot analysis to predict future concentrations of crime in London. Kim Rossmo, Quint Thurman, J.D. Jamieson and Kristine Egan analyze the spatial and temporal concentrations of illegal border crossings along a stretch of the Texas-Mexico border. They establish connections between these hot spots and a series of physical, temporal and spatial constraints on movement. Jerry Ratcliffe and George Rengert explore the dynamics of near repeat shootings in Philadelphia and find consistent escalations in the risk of shootings within one city block and two weeks of any initial shooting incident.

Two papers follow different and very complex lines of analysis. Aili Malm, Bryan Kinney and Nahanni Pollard merge spatial analysis of the distribution of marijuana cultivation sites in Vancouver with a social network analysis of the marijuana growers and their criminal associates. They discover spatial patterns in the criminal network consistent with the expectations of crime pattern theory. Elizabeth Groff uses agent-based simulation modeling 
to explore the spatial and temporal aspects of routine activity theory. She shows how a computational environment can be used to run experiments that cannot reasonably be conducted in real settings both for ethical reasons and because of time and cost constraints.

Martha Smith's article explores the security requirements of female public transit users. She merges information about victimization patterns and patterns of fear through use of a total journey analysis that looks at security needs flowing from the many different situations encountered over the course of a public transit journey from origin to destination. In keeping with another of the important ECCA traditions, the article closes with detailed attention to the policy and situational intervention implications of the study.

This set of papers demonstrates the depth of enquiry found at ECCA. It also provides a glimpse into the future of an approach to crime analysis that offers real utility to law enforcement and security professionals in the continued pursuit of crime reduction.

Paul Brantingham

School of Criminology, Simon Fraser University, Burnaby, British Columbia, Canada

E-mail: branting@sfu.ca 